\title{
Lower Limb Force and Power Production and Its Relation to Body Composition in 14- to 15-Year-Old Kosovan Adolescents
}

\author{
Faton Tishukaj', Ismet Shalaj², Masar Gjaka3 ${ }^{3}$ Barbara Wessner ${ }^{2}$, Harald Tschan ${ }^{2 *}$ \\ ${ }^{1}$ Faculty of Physical Education and Sports, University of Pristina "Hasan Prishtina", Pristina, Kosovo \\ ${ }^{2}$ Centre for Sport Science and University Sports, University of Vienna, Vienna, Austria \\ ${ }^{3}$ Department of Sport and Movement Science, University for Business and Technology, Pristina, Kosovo \\ Email: faton.tishukaj@uni-pr.edu, ishalaj1@hotmail.com, masar.gjaka@ubt-uni.net, \\ barbara.wessner@univie.ac.at, `harald.tschan@univie.ac.at
}

How to cite this paper: Tishukaj, F., Shalaj, I., Gjaka, Wessner, M., B., \& Tschan, H. (2021). Lower Limb Force and Power Production and Its Relation to Body Composition in 14- to 15-Year-Old Kosovan Adolescents. Advances in Physical Education, $11,61-81$.

https://doi.org/10.4236/ape.2021.111005

Received: December 7, 2020

Accepted: February 5, 2021

Published: February 8, 2021

Copyright $\odot 2021$ by author(s) and Scientific Research Publishing Inc. This work is licensed under the Creative Commons Attribution International License (CC BY 4.0).

http://creativecommons.org/licenses/by/4.0/

\begin{abstract}
Adiposity-related joint loading and unequal force distribution during jumping tasks place additional stress on soft tissue structures of the non-dominant leg, which may reduce performance and is likely to increase injury risk and the development of musculoskeletal degenerative diseases. Movement-related dysfunctions of children and adolescents are of particular interest because they represent modifiable risk factors that can be targeted by intervention programs, which may decrease degenerative changes later in life. Therefore, this study aims to determine the influence of body weight and obesity on force and power production as well as the prevalence of limb asymmetry in adolescents. A cross-sectional study including 354 adolescents (195 boys: 14.6 \pm 0.4 years; 159 girls: $14.5 \pm 0.4$ years) was performed. Anthropometric parameters and countermovement jump (force and power parameters) were assessed using a dual force plate. Countermovement jump and 20-m sprint performances were significantly influenced by BMI categories $(p<0.001)$, with obese subjects performing worse than their normal weight colleagues do. Although peak fore and peak power were significantly higher, especially in obese adolescents $(p<0.001)$, relative to body weight peak power was worse in overweight and obese adolescents $(p<0.001)$. The proportion of adolescents with limb asymmetry (from power production values) was markedly higher in obese children when compared to other BMI categories. The present study revealed differences in force and power production and inter-limb symmetry measurements related to BMI categories. Therefore, with consideration of anthropometric characteristics, the assessment of ground reaction forces might provide an accurate approach for the assessment,
\end{abstract}


screening and monitoring motor performance as well as bilateral differences in children and adolescents.

\section{Keywords}

Physical Fitness, Limb Asymmetry, Obesity, Overweight, Lower Extremity, Motoric Tests

\section{Introduction}

Pediatric obesity is globally considered as one of the most severe public health challenges of the $21^{\text {st }}$ century, affecting all countries worldwide. Within the last four decades the number of school-aged children and adolescents with obesity has increased more than 10-fold (Collaboration, 2017). Obesogenic factors such as energy-dense diets and low levels of physical activity are associated with this childhood epidemic (Maffeis, Zaffanello, \& Schutz, 1997), resulting in impaired physical fitness (Lafortuna, Fumagalli, Vangeli, \& Sartorio, 2002; O’Malley, Hussey, \& Roche, 2012), and increased risk for chronic diseases later in life (Boreham \& Riddoch, 2001; Dwyer et al., 2009). Moreover, in obese children and adolescents, skeletal muscle alterations with increments in muscle lipid content have been observed, raising concerns about changes in muscle properties and their function (Lee, Guerra, \& Arslanian, 2010). Hence, there is supporting evidence that among obese subjects biomechanical limitations appear, impairing muscle force and power development especially during propulsion activities (Blimkie, Sale, \& Bar-Or, 1990; Lafortuna, Maffiuletti, Agosti, \& Sartorio, 2005). Childhood obesity is also associated with reduced muscle unit activation (Blimkie et al., 1990) faster neuromuscular fatigue (Garcia-Vicencio et al., 2015), increased joint stress (Shultz, Hills, Sitler, \& Hillstrom, 2010), and increased postural sway (Goulding, Jones, Taylor, Piggot, \& Taylor, 2003). Furthermore, obesity can cause pelvic obliquity which may result in altered gait kinematics and muscular asymmetries (Hills \& Parker, 1992), imposing higher risks of injury occurrence even during walking (Lerner, Board, \& Browning, 2014; Lerner, Shultz, Board, Kung, \& Browning, 2014), and of developing musculoskeletal disorders (Grimes \& Legg, 2004).

Inter-limb asymmetry measurements have become an increasingly used practice among clinicians, sport scientists and practitioners in quantifying functional deficits as they have shown to be associated with decrements in physical performance and increased injury risk (Fort-Vanmeerhaeghe et al., 2020; Madruga-Parera et al., 2019; Mala et al., 2020; Schmitt, Paterno, Ford, Myer, \& Hewett, 2015; Steidl-Muller, Hildebrandt, Muller, Fink, \& Raschner, 2018). In any given task, the reduced physical capacity of the weaker limb to both produce and absorb force is likely to increase the risk of acute and/or overuse injury and the development of musculoskeletal degenerative diseases (Bell, Sanfilippo, Binkley, \& Heiderscheit, 2014; Paterno et al., 2010; Shimizu et al., 2019). The underlying 
mechanisms of joint pain (particularly in the knee and ankle) in obesity may be partially due to adiposity-related joint loading and unequal force distribution (Bout-Tabaku et al., 2014; Guddal et al., 2020; Yoo, Cho, Lim, \& Kim, 2014). Pain with physical activity initiates a downward spiral of avoidance of activity and muscle disuse; over time, sedentary behavior worsens muscle weakness and contributes to muscle wasting. Therefore, movement-related dysfunctions of children and adolescents are of particular interest because they are considered modifiable risk factors that can be targeted by intervention programs, which may decrease injury risk and degenerative changes later in life. However, currently there is limited information regarding the amount of lower limb asymmetry that exists in children and adolescents and no studies to date have compared the influence of body mass category on limb asymmetries. In addition, musculoskeletal fitness is considered a crucial component of the maintenance of overall health and fitness status (Smith et al., 2014) and the inability to perform muscular fitness tasks is associated with poorer health (Rodriguez Valero, Gualteros, Torres, Umbarila Espinosa, \& Ramirez-Velez, 2015). Vertical jumps (power) and sprints (speed) account to parameters of skill-related musculoskeletal fitness (American College of Sports Medicine, 2010) and could be used to assess lower limb performance when performed under laboratory conditions (Castro-Pinero et al., 2009; Lake et al., 2018). The countermovement jump, with or without arm swing, and the 20-meter sprinting tests are valid and amongst the most frequently used tests for lower limb force and power measurement in epidemiologic studies in youth (Castro-Pinero et al., 2010; Castro-Pinero et al., 2009; Maly, Zahalka, Mala, \& Cech, 2015). Scientific evidence has shown that obese children and adolescents display reductions of aerobic power compared to normal weight counterparts (Gidding et al., 2004; Laurson, Saint-Maurice, Welk, \& Eisenmann, 2017; Loftin et al., 2001), but fewer studies analyzed skill-related anaerobic performance in obese youth. In addition, lower limb asymmetry in sports has been well documented (Buckeridge, Hislop, Bull, \& McGregor, 2012; Luk, Winter, O'Neill, \& Thompson, 2014; Steidl-Muller et al., 2018; Trivers et al., 2014), but in studies including school children and adolescents the field needs further investigations. Therefore, the aim of this study was to provide an insight of absolute and relative force and power production, lower limb asymmetries and their relation to body composition in 14- to 15 -year-old pupils.

\section{Methods}

\subsection{Participants and Study Design}

A sample of 354 pupils from four different schools in Kosovo with an age of 14.5 \pm 0.4 years volunteered to participate in this cross-sectional study and completed all tests. The number of male students was slightly higher compared to girls (55.1\% males versus $44.9 \%$ females). All the participants and their parents provided written informed consent before the commencement of the study. Ethical permission was obtained by the Ethics Committee of the University Clinical 
Centre of Kosovo (Ethics decision no 6616) following the authorization from the school management. Illness- and injury-free participants were included into the data pool for final analysis.

\subsection{Anthropometry}

Height was measured to the nearest $0.5 \mathrm{~cm}$ with a portable stadiometer (Seca, Hamburg, Germany) and body mass was measured to the nearest $0.1 \mathrm{~kg}$ using a digital scale (Seca, Hamburg, Germany) with participants being barefoot and wearing athletic attire. Body mass index (BMI) was calculated by dividing body mass $(\mathrm{kg})$ by height $(\mathrm{m})$ squared, and participants were classified as thin, normal weight, overweight and obese using age- and gender-specific cut-off points as proposed by International Obesity Task Force (Cole, Bellizzi, Flegal, \& Dietz, 2000; Cole, Flegal, Nicholls, \& Jackson, 2007). In addition, skinfold measurement were performed at four sites of the upper body (biceps, triceps, subscapular and suprailiac site) and body fat percentage was calculated from body density using the gender-specific equations by Weststrate and Deurenberg (Weststrate \& Deurenberg, 1989).

\subsection{Motor Ability Tests}

Maximum linear running speed was measured using an electronic timing system (Brower Timing Systems, USA) with a precision of $0.01 \mathrm{~s}$. Participants were instructed to sprint with maximum effort over a $20-\mathrm{m}$ distance. Sprint times were recorded by photocell gates mounted $1 \mathrm{~m}$ above floor level placed $40 \mathrm{~cm}$ after the start line and after 20 meters, respectively. Sprints were initiated from a standing position allowing participants to start on their own initiative following a ready signal given by the test operator. All subjects performed two trials, with 5 -minutes of recovery between trials, using the best score for data analyses.

\subsection{Force, Power and Limb Symmetry Index Measurement}

A two sectional quadratic mechanography platform (Leonardo Mechanograph, Galileo Novotec Medical GmbH, Germany), with a sensor sampling rate of 800 $\mathrm{Hz}$, was used to measure force and power production of the participants, where only the vertical component of the force was taken into account. The force plate was calibrated after every transportation from lab to school and from school to school, respectively. Using the approach established by Cavagna (1975), the software uses time and force data to calculate the power for both legs and jump height, respectively (Cavagna, 1975). Participants were instructed to perform a countermovement at an angle of approximately 90 degrees and jump explosively as high as possible while keeping their hands at their hips and their knees straight during the flight time. The testing procedure was explained in detail to each participant and each of them had the possibility to perform one free of measurement trial before the testing procedure started. Thereafter, the best result out of two measurement trials was recorded for further statistical analysis. 
The minimum resting period between the trials was 5 minutes. Relative values were calculated by dividing the maximum values by the participant's body mass. Limb symmetry indices (LSI) for force and power (LSIforce and LSIpower) were calculated by dividing the higher value obtained by either the right or left limb by the lower value of the other limb multiplied by 100 (Steidl-Muller et al., 2018). A value difference between the limbs greater than $15 \%$ was considered as an asymmetrical outcome (Maly et al., 2015).

\subsection{Statistical Analysis}

A two-way ANOVA was conducted to examine the main effects of gender and body composition category on force and power production as well as on both LSIs. Differences in LSI between right and left limbs were calculated by paired t-test. Effect sizes were provided as partial $\eta^{2}$ (two-way ANOVA) or Cohen's d (paired t-test). Pearson's product-moment correlations were run to assess potential associations between force and power measurements with age, anthropometric and motoric test variables, as well as limb asymmetry. The strength of correlations was indicated by interpreting the Pearson correlation coefficients according to Mukaka (Mukaka, 2012) (0.9 to 1.0: very high correlation, 0.7 to 0.9 : high correlation; 0.5 to 0.7 : moderate correlation; 0.3 to 0.5 ; low correlation; 0.0 to 0.3: negligible correlation). In order to explain the contribution of age, sex, body composition, and power and force production to the functional tests (sprint and counter movement jump) multiple linear regression models were developed. Data are presented as mean \pm standard deviations unless otherwise specified. A p-value of less than 0.05 was regarded as statistically significant and all analyses were conducted using IBM SPSS Statistics Version 25.0 (IBM Corporation, USA).

\section{Results}

\subsection{Participant Characteristics}

Table 1 shows the relationship between body composition and body fat on objectively measured motoric tests results. Statistical analysis did not indicate age differences between thin, normal weight, overweight and obese adolescents or between boys and girls $(p>0.05)$. As expected BMI was different between boys and girls $\left(\mathrm{F}(1,346)=7.33, p=0.007\right.$, partial $\left.\eta^{2}=0.021\right)$ and BMI categories $(\mathrm{F}$ $(3,346)=500.05, p<0.001$, partial $\left.\eta^{2}=0.813\right)$. Similarly, body fat differed between gender $\left(\mathrm{F}(1,346)=202.15, p<0.001\right.$, partial $\left.\eta^{2}=0.369\right)$ and BMI categories $\left(\mathrm{F}(3,346)=198.81, p<0.001\right.$, partial $\left.\eta^{2}=0.633\right)$, whereby there was a significant interaction between gender and BMI categories for body fat $(F(3,346)$ $=2.912, p=0.034$, partial $\left.\eta^{2}=0.025\right)$ as the increases in body fat with higher BMI categories were more pronounced in boys $(+48.7 \%,+105 \%$ compared to normal weight) than in girls $(+26.2 \%,+48.8 \%$ compared to normal weight).

There was no statistically significant interaction between gender and BMI categories for $\operatorname{CMJ}\left(\mathrm{F}(3,346)=1.98, p=0.117\right.$, partial $\left.\eta^{2}=0.017\right)$ and for $20-\mathrm{m}$ 
Table 1. Descriptive characteristics of the study participants based on BMI categories.

\begin{tabular}{|c|c|c|c|c|c|c|c|c|c|c|c|}
\hline & \multicolumn{4}{|c|}{ Boys } & \multicolumn{4}{|c|}{ Girls } & \multicolumn{3}{|c|}{ p-values } \\
\hline & Low weight & $\begin{array}{c}\text { Normal } \\
\text { weight }\end{array}$ & Overweight & Obese & Low weight & $\begin{array}{c}\text { Normal } \\
\text { weight }\end{array}$ & Overweight & Obese & sex & $\begin{array}{c}\text { BMI } \\
\text { category }\end{array}$ & $\begin{array}{c}\text { Sex \& } \\
\text { BMI } \\
\text { category }\end{array}$ \\
\hline N (\%) & $13(6.7 \%)$ & $127(65.1 \%)$ & 37 (19.0\%) & $8(9.2 \%)$ & $13(8.2 \%)$ & $116(73.0 \%)$ & $21(13.2 \%)$ & $9(5.8 \%)$ & & & \\
\hline $\begin{array}{c}\text { Age } \\
\text { (years) }\end{array}$ & $14.6 \pm 0.4$ & $14.6 \pm 0.4$ & $14.5 \pm 0.4$ & $14.7 \pm 0.3$ & $14.5 \pm 0.3$ & $14.5 \pm 0.4$ & $14.6 \pm 0.4$ & $14.6 \pm 0.3$ & 0.454 & 0.780 & 0.362 \\
\hline $\begin{array}{c}\text { BMI } \\
\left(\mathrm{kg} / \mathrm{m}^{2}\right)\end{array}$ & $15.7 \pm 1.2^{* * *}$ & $19.8 \pm 1.7$ & $25.1 \pm 1.2^{* * *}$ & $31.0 \pm 2.0^{* * *}$ & $16.4 \pm 0.6^{* * *}$ & $20.4 \pm 1.8$ & $25.8 \pm 1.7^{7 * *}$ & $31.9 \pm 3.1^{* * *}$ & 0.007 & $<0.001$ & 0.914 \\
\hline $\begin{array}{c}\text { Body } \\
\text { fat (\%) }\end{array}$ & $11.5 \pm 1.4^{* *}$ & $15.4 \pm 3.4$ & $22.9 \pm 5.0^{* * *}$ & $31.6 \pm 3.9^{* * *}$ & $19.4 \pm 2.2^{* * *}$ & $24.8 \pm 3.2$ & $31.3 \pm 3.0^{* * *}$ & $36.9 \pm 2.0^{* * *}$ & $<0.001$ & $<0.001$ & 0.034 \\
\hline $\begin{array}{l}\text { CMJ } \\
(\mathrm{cm})\end{array}$ & $37.0 \pm 6.7$ & $39.0 \pm 5.4$ & $37.3 \pm 5.2$ & $33.1 \pm 5.5^{* * *}$ & $32.7 \pm 4.0$ & $29.9 \pm 4.9$ & $27.5 \pm 4.7$ & $23.1 \pm 2.7^{* * *}$ & $<0.001$ & $<0.001$ & 0.117 \\
\hline $\begin{array}{c}20 \mathrm{~m} \\
\text { sprint (s) }\end{array}$ & $3.67 \pm 0.34$ & $3.60 \pm 0.23$ & $3.75 \pm 0.24^{\star *}$ & $3.96 \pm 0.28^{* * *}$ & $4.18 \pm 0.31$ & $4.29 \pm 0.30$ & $4.37 \pm 0.28$ & $4.71 \pm 0.35^{* * *}$ & $<0.001$ & $<0.001$ & 0.268 \\
\hline
\end{tabular}

Data are expressed as means \pm standard deviations; Main and interaction effects between sex and BMI categories as analysed by two-factorial ANOVA followed by Bonferroni post hoc analyses; Asterisks denote differences to normal weight within the respective $\operatorname{sex}\left({ }^{* *} p<0.01,{ }^{* *} p<0.001\right)$. Abbreviations: BMI (body mass index); CMJ (countermovement jump).

sprint $\left(\mathrm{F}(3,346)=1.32, p=0.268\right.$, partial $\left.\eta^{2}=0.011\right)$, but significant main effects on CMJ were revealed for gender $\left(\mathrm{F}(1,346)=100.67, p<0.001\right.$, partial $\eta^{2}$ $=0.225)$ and BMI categories $\left(\mathrm{F}(3,346)=12.84, p<0.001\right.$, partial $\left.\eta^{2}=0.100\right)$ with significantly lower values for girls and obese adolescents (for detailed data see Table 1). Similarly, significant main effects on 20-m sprint were detected for gender $\left(\mathrm{F}(1,346)=218.71, p<0.001\right.$, partial $\left.\eta^{2}=0.387\right)$ and BMI categories $(\mathrm{F}$ $(3,346)=17.54, p<0.001$, partial $\left.\eta^{2}=0.132\right)$ with significantly worse sprinting times for girls and overweight or obese (Table 1 ).

\subsection{Force, Power and Body Composition}

No interaction effect between gender and BMI categories on peak force could be observed $\left(\mathrm{F}(3,346)=1.67, p=0.173\right.$, partial $\left.\eta^{2}=0.014\right)$. However, there was a significant main effect of BMI category on peak force $(\mathrm{F}(3,346)=40.49, p<$ 0.001 , partial $\eta^{2}=0.260$ ). Bonferroni-corrected post hoc tests revealed that higher BMI categories resulted in higher peak force production $(p<0.05$ for all comparisons). Obese children had a $34.8 \%$ higher peak force and thin children had a $25.4 \%$ lower peak force production than their normal weight counterparts. Gender had no impact on peak force $\left(\mathrm{F}(1,346)=0.05, p=0.816\right.$, partial $\eta^{2}=$ 0.000) (Figure 1(a)).

When regarding relative peak force, no interaction effect between gender and BMI categories was observed $\left(\mathrm{F}(3,346)=0.42, p=0.740\right.$, partial $\left.\eta^{2}=0.004\right)$, but again there was a significant main effect of BMI category on relative peak force ( $\mathrm{F}$ $(3,346)=5.66, p=0.001$, partial $\left.\eta^{2}=0.047\right)$. Bonferroni-corrected post hoc tests revealed that for obese children a lower relative peak force production was observed in comparison to normal weight $(-16.6 \%, p<0.001)$. Gender had no impact on relative peak force $\left(\mathrm{F}(1,346)=2.04, p=0.154\right.$, partial $\left.\eta^{2}=0.006\right)($ Figure $1(b))$. 

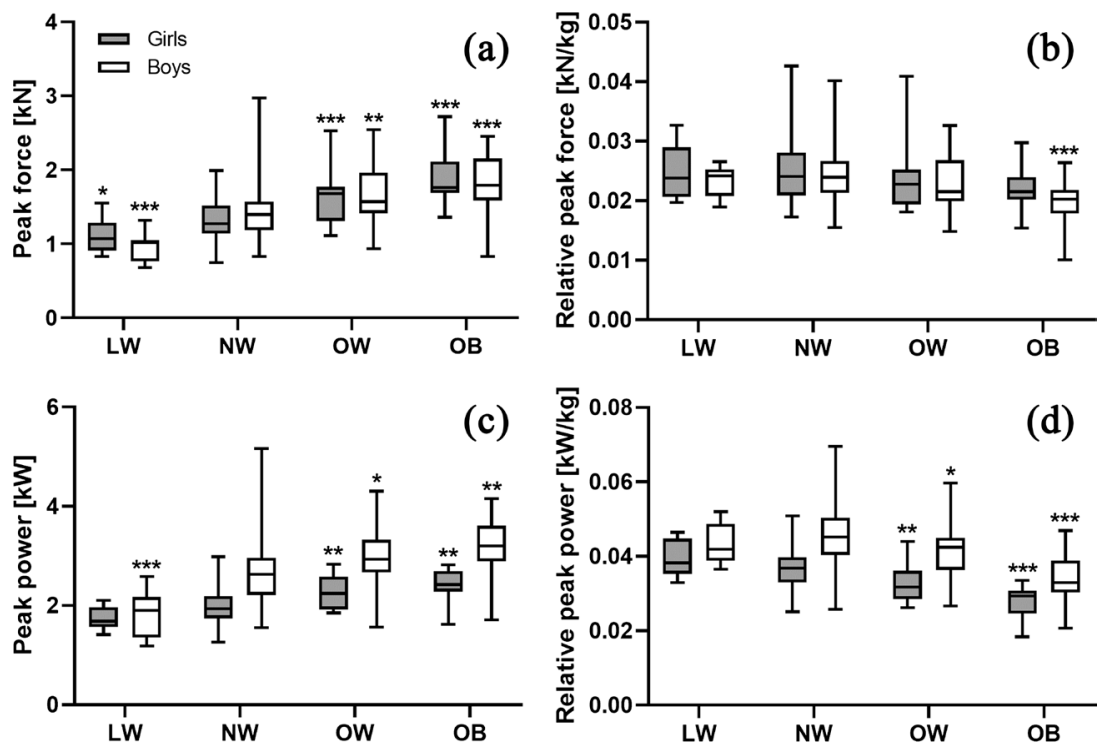

Figure 1. Influence of BMI on peak force and power production. Grey bars denote girls and white bars represent boys. Asterisks denote significant differences to normal weight within the respective sex based on ANOVA followed by Bonferroni-corrected post hoc analyses $\left({ }^{\star} p<0.05,{ }^{* *} p<0.01,{ }^{* *} p<0.001\right)$. Abbreviations: LW (low weight); NW (normal weight); OW (overweight); OB (obese).

With respect to peak power, a small interaction effect between gender and BMI categories was observed with peak power of girls increasing to a lower extent than those of the boys $\left(\mathrm{F}(3,346)=3.13, p=0.026\right.$, partial $\left.\eta^{2}=0.026\right)$. There was a significant main effect of BMI categories on this parameter $(\mathrm{F}(3,346)=$ 23.07, $p<0.001$, partial $\eta^{2}=0.167$ ). Corrected post hoc tests using Bonferroni model revealed that both higher BMI categories (overweight and obese) resulted in higher peak power production in comparison to normal weight $(+16.7 \%$ and $+24.9 \%$, both $p<0.001)$, whereas thinner children reported a $23.6 \%$ lower peak power than normal weight children $(p<0.001)$. Gender had an impact on peak power, as boys showed higher performance compared to girls $(\mathrm{F}(1,346)=$ 48.63, $p<0.001$, partial $\eta^{2}=0.123$ ) (Figure $1(\mathrm{c})$ ).

The before-mentioned interaction effect between gender and BMI category was lost, when dividing peak power by body weight referred to relative peak power $\left(\mathrm{F}(3,346)=1.00, p=0.394\right.$, partial $\left.\eta^{2}=0.009\right)$. Nevertheless, a significant main effect of BMI categories on relative peak power was observed $(\mathrm{F}(3,346)=$ 21.08, $p<0.001$, partial $\left.\eta^{2}=0.155\right)$. Bonferroni-corrected post hoc tests revealed that overweight and obese children showed a lower relative peak power production $(-8.2 \%$ and $-21.9 \%, p<0.001)$ than normal weight children, whereas thin children performed similarly $(p>0.05)$. Gender had an impact on relative peak power, with boys performing better compared to girls $(\mathrm{F}(1,346)=40.02, p<$ 0.001, partial $\left.\eta^{2}=0.104\right)$ (Figure $1(d)$ ).

\subsection{Limb Asymmetry}

As shown in Table 2, peak force and peak power were significantly higher in the 
right limbs as compared to the left limbs (peak force: T353 $=-5.043, p<0.001$, d $=0.268$; peak power: T353 $=-3.890, p<0.001, \mathrm{~d}=0.207)$. In $13.6 \%$ of the participants, limb asymmetries above $15 \%$ were detected when LSI was calculated using peak force as underlying factor, whereas only $4.5 \%$ had asymmetries in power production between left and right leg.

A two-factorial ANOVA revealed that there was no interaction between gender and BMI category on both peak force and peak power (peak force: $\mathrm{F}(3$, $346)=1.43, p=0.235$, partial $\eta^{2}=0.012$; peak power: $\mathrm{F}(3,346)=0.27, p=$ 0.849 , partial $\left.\eta^{2}=0.002\right)$. However, a small significant main effect of gender could be detected for peak force $\left(\mathrm{F}(1,346)=5.07, p=0.025\right.$, partial $\left.\eta^{2}=0.014\right)$ with girls showing slightly higher limb asymmetries than boys, irrespective of BMI category. In contrast an influence of BMI categories on peak power was revealed $\left(\mathrm{F}(3,346)=2.89, p=0.036\right.$, partial $\left.\eta^{2}=0.024\right)$. Bonferroni-corrected post hoc analyses detected a higher LSIpower for obese as compared to underweight children $(p=0.040)$. The proportion of adolescents with limb asymmetry (from power production values) separated for BMI categories are shown in Figure 2.

\subsection{Correlations}

Associations between lower limb peak force, power production, sports motoric tests and anthropometric characteristics are shown in Table 2. Peak force showed low to moderate correlations with anthropometric variables (BMI: $\mathrm{r}=0.557, p<$ 0.001 ; body mass: $\mathrm{r}=0.646, p<0.001$; height $\mathrm{r}=0.404, p<0.001$; body fat

Table 2. Lower limb asymmetry for peak force and power.

\begin{tabular}{ccccccc}
\hline & Left limb & Right limb & Difference & $\begin{array}{c}\text { p-value for } \\
\text { difference }\end{array}$ & LSI (\%) & $\begin{array}{c}\text { Asymmetry } \\
\text { (n, \%) }\end{array}$ \\
\hline Peak force $(\mathrm{kN})$ & $0.71 \pm 0.18$ & $0.73 \pm 0.19$ & $0.015 \pm 0.073$ & $<0.001$ & $8.4 \pm 7.2$ & $48(13.6 \%)$ \\
Peak power $(\mathrm{kW})$ & $1.19 \pm 0.32$ & $1.21 \pm 0.33$ & $0.023 \pm 0.084$ & $<0.001$ & $5.8 \pm 4.7$ & $16(4.5 \%)$ \\
\hline
\end{tabular}

Data are expressed as means \pm standard deviations; Differences between right and left limb were calculated by paired t-test; LSI (limb symmetry index).

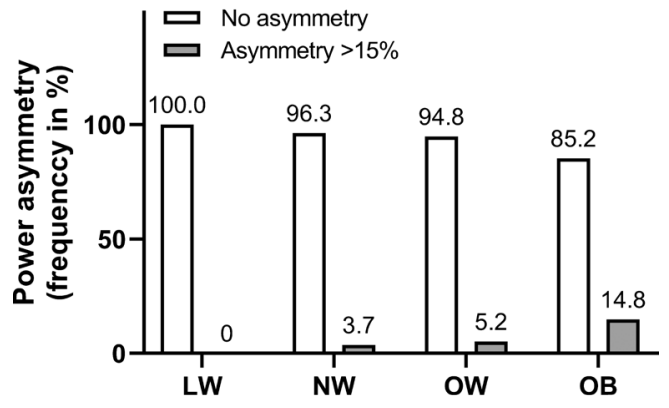

Figure 2. Influence of BMI on limb asymmetry. White bars represent the proportion of adolescents with LSI below 15\% within a BMI category. Grey bars show proportion of adolescents with limb asymmetry. Asterisks denote significant differences to normal weight within the respective sex based on ANOVA followed by Bonferroni-corrected post hoc analyses $\left({ }^{\star} p<0.05,{ }^{* *} p<0.01,{ }^{* *} p<0.001\right)$. Abbreviations: LW (low weight); NW (normal weight); OW (overweight); OB (obese). 
percentage: $r=0.310, p<0.001)$ and age $(r=0.242, p<0.001)$. Also peak power showed low to moderate positive correlations to body mass ( $\mathrm{r}=0.614, p<$ $0.001)$, height $(\mathrm{r}=0.622, p<0.001)$, BMI $(\mathrm{r}=0.413, p<0.001)$, and age $(\mathrm{r}=$ $0.250, p<0.001)$. In contrast to peak force, peak power was positively associated to $\mathrm{CMJ}(\mathrm{r}=0.504, p<0.001)$ and negatively to 20 -m sprint time $(\mathrm{r}=-0.472, p<$ $0.001)$, whereby the correlation coefficients even increased when peak power was divided by body weight (CMJ: $\mathrm{r}=0.642, p<0.001 ; 20$ - $\mathrm{m}$ sprint time: $\mathrm{r}=-0.580$, $p<0.001)$. LSIs calculated based on either power or force measurement were not correlated to any of the parameters besides a low correlation between LSI power and 20-m sprint $(\mathrm{r}=0.123, p=0.021)$.

Table 3 and Table 4 presents the results derived from the multiple linear regression models, which partially explain the variation for countermovement jump and sprinting time as outcome variables. Model 1 shows that for both variables, sex accounted for $38.2 \%$ for the CMJ and already $55.5 \%$ for the $20-\mathrm{m}$ sprint, respectively. Adding body fat percentage to the model (model 2) yielded improved predictability and accounted for $46.2 \%$ of the variation of CMJ and $61.9 \%$ of the 20 -m sprint, respectively. In addition, sex, body fat percentage and peak power further improved the determination effect of both outcome variables (model 3) with $57.8 \%$ for the CMJ and $65.9 \%$ for the 20 -m sprint time. Finally, the addition of peak force to the latter model increased the predictability to $66.3 \%$ for $\mathrm{CMJ}$ and $70.0 \%$ for 20 -m sprint time, respectively.

\section{Discussion}

The present study evaluated force and power production as well as lower limb asymmetry of different body composition categories among 14- to 15-year-old pupils. The main findings were that obese adolescents showed to have higher absolute peak force and power production and lower CMJ- and 20-m sprinting results compared to normal weight counterparts regardless of gender. Contrary,

Table 3. Correlations of limb force, power and LSIs with motoric tests and anthropometric characteristics.

\begin{tabular}{|c|c|c|c|c|c|c|c|}
\hline & $\begin{array}{l}\text { CMJ } \\
(\mathrm{cm})\end{array}$ & $\begin{array}{c}20 \mathrm{~m} \\
\text { sprint }(\mathrm{s})\end{array}$ & $\begin{array}{c}\text { Age } \\
\text { (years) }\end{array}$ & $\begin{array}{l}\text { Height } \\
\text { (m) }\end{array}$ & $\begin{array}{c}\text { Body mass } \\
(\mathrm{kg})\end{array}$ & $\begin{array}{c}\text { BMI } \\
\left(\mathrm{kg} / \mathrm{m}^{2}\right)\end{array}$ & $\begin{array}{c}\text { Body } \\
\text { fat (\%) }\end{array}$ \\
\hline Peak force $(\mathrm{kN})$ & 0.030 & -0.017 & $0.242^{\star * *}$ & $0.404^{* * *}$ & $0.646^{* * *}$ & $0.557^{\star * *}$ & $0.310^{* * *}$ \\
\hline $\begin{array}{l}\text { Relative peak force } \\
\qquad(\mathrm{kN} / \mathrm{kg})\end{array}$ & 0.035 & 0.004 & $0.136^{*}$ & -0.066 & $-0.219^{* * *}$ & $-0.222^{* * *}$ & $-0.141^{\star *}$ \\
\hline Peak power $(\mathrm{kW})$ & $0.504^{* * *}$ & $-0.472^{\star * *}$ & $0.250^{\star * *}$ & $0.622^{\star * *}$ & $0.614^{\star * \star}$ & $0.413^{\star * *}$ & -0.029 \\
\hline $\begin{array}{l}\text { Relative peak power } \\
\qquad(\mathrm{kW} / \mathrm{kg})\end{array}$ & $0.642^{* * *}$ & $-0.580^{\star * *}$ & $0.171^{* *}$ & $0.251^{\star * *}$ & $-0.182^{\star *}$ & $-0.332^{\star * *}$ & $-0.538^{\star * *}$ \\
\hline $\operatorname{LSI}_{\text {force }}(\%)$ & -0.077 & $0.123^{*}$ & -0.044 & 0.000 & 0.088 & 0.101 & 0.097 \\
\hline $\mathrm{LSI}_{\text {power }}(\%)$ & 0.027 & 0.029 & 0.000 & -0.028 & 0.009 & 0.020 & 0.049 \\
\hline
\end{tabular}

Data represent Pearson correlation coefficients (r), Significant correlations are marked with asterisks $\left({ }^{*} p<\right.$ $0.05,{ }^{* *} p<0.01,{ }^{* *} p<0.001$ ). Abbrevations: BMI (body mass index), CMJ (countermovement jump), LSI (limb symmetry index) 
Table 4. Multiple linear regression models.

\begin{tabular}{|c|c|c|c|c|}
\hline & Models & $\beta \pm S E$ & $\mathrm{p}$-Value & Adjusted $\mathrm{R}^{2}(\%)$ \\
\hline \multirow{23}{*}{$\begin{array}{l}\text { Countermovement } \\
\text { Jump }(\mathrm{cm})\end{array}$} & 1 & & & 38.2 \\
\hline & Constant & $20.81 \pm 0.94$ & $<0.001$ & \\
\hline & Sex & $8.60 \pm 0.58$ & $<0.001$ & \\
\hline & 2 & & & 46.2 \\
\hline & Constant & $32.22 \pm 1.80$ & $<0.001$ & \\
\hline & Sex & $5.94 \pm 0.65$ & $<0.001$ & \\
\hline & Body fat (\%) & $-0.34 \pm 0.04$ & $<0.001$ & 57.8 \\
\hline & 3 & & & \\
\hline & Constant & $31.5 \pm 1.60$ & $<0.001$ & \\
\hline & Sex & $1.49 \pm 0.73$ & 0.043 & \\
\hline & Body fat (\%) & $-0.50 \pm 0.04$ & $<0.001$ & \\
\hline & Peak power $(\mathrm{kW})$ & $4.64 \pm 0.47$ & $<0.001$ & \\
\hline & 4 & & & 66.3 \\
\hline & Constant & $33.50 \pm 1.44$ & $<0.001$ & \\
\hline & Sex & $0.11 \pm 0.67$ & 0.867 & \\
\hline & Body fat (\%) & $-0.38 \pm 0.04$ & $<0.001$ & \\
\hline & Peak power $(\mathrm{kW})$ & $9.70 \pm 0.68$ & $<0.001$ & \\
\hline & Peak force $(\mathrm{kN})$ & $-10.20 \pm 1.08$ & $<0.001$ & \\
\hline & 5 & & & 66.4 \\
\hline & Constant & $33.67 \pm 1.07$ & $<0.001$ & \\
\hline & Body fat (\%) & $-0.38 \pm 0.05$ & $<0.001$ & \\
\hline & Peak power (kW) & $9.75 \pm 0.57$ & $<0.001$ & \\
\hline & Peak force $(\mathrm{kN})$ & $-10.24 \pm 1.05$ & $<0.001$ & \\
\hline \multirow{18}{*}{ 20-m Sprint (s) } & 1 & & & 55.5 \\
\hline & Constant & $4.97 \pm 0.05$ & $<0.001$ & \\
\hline & Sex & $-0.65 \pm 0.03$ & $<0.001$ & \\
\hline & 2 & & & 61.9 \\
\hline & Constant & $4.33 \pm 0.09$ & $<0.001$ & \\
\hline & Sex & $-0.50 \pm 0.03$ & $<0.001$ & \\
\hline & Body fat (\%) & $0.02 \pm 0.002$ & $<0.001$ & \\
\hline & 3 & & & 65.9 \\
\hline & Constant & $4.35 \pm 0.90$ & $<0.001$ & \\
\hline & Sex & $-0.34 \pm 0.04$ & $<0.001$ & \\
\hline & Body fat (\%) & $0.26 \pm 0.003$ & $<0.001$ & \\
\hline & Peak power $(\mathrm{kW})$ & $-0.17 \pm 0.03$ & $<0.001$ & \\
\hline & 4 & & & 70.0 \\
\hline & Constant & $4.27 \pm 0.09$ & $<0.001$ & \\
\hline & Sex & $-0.28 \pm 0.04$ & $<0.001$ & \\
\hline & Body fat (\%) & $0.02 \pm 0.002$ & $<0.001$ & \\
\hline & Peak power $(\mathrm{kW})$ & $-0.40 \pm 0.04$ & $<0.001$ & \\
\hline & Peak force $(\mathrm{kN})$ & $0.45 \pm 0.06$ & $<0.001$ & \\
\hline
\end{tabular}

Covariates are listed with parameter estimates and standard errors $(\beta \pm S E)$ and with $p$-values. 
relative peak force and power production values in obese adolescents were smaller, compared to normal weight and thin cohorts, respectively. Similar results reporting higher peak and relative force and power values were also reported previously by other researchers studying obese and non-obese youth (Lazzer, Pozzo, Rejc, Antonutto, \& Francescato, 2009; Rauch et al., 2012; Thivel et al., 2011; Tsiros et al., 2013). It would have been interesting to determine muscle mass as the direct contributor to force and power, but the current study included a relatively large number of participants measured directly within their school settings. Consequently, it was not possible to measure body composition with more detailed outcomes. Nevertheless, equations attempting to estimate children and adolescent's fat-free mass (FFM) using anthropometric variables have been published, but these equations require sitting height, peak height velocity and other parameters that were not assessed by the research group (Machado, Oikawa, \& Barbanti, 2013). However, studies analyzing force and power production with respect to FFM found no difference between children and adolescents and their weight status (Duche et al., 2002; Lazzer et al., 2009; Maffiuletti, Jubeau, Agosti, De Col, \& Sartorio, 2008). These findings emphasize a lower efficiency of obese subjects compared to their lean counterparts. In reference to that, Abdelmoula and colleagues (Abdelmoula et al., 2012) found that in comparison to lean adolescents obese ones produce significantly higher amounts of absolute peak force, and also higher relative peak force in relation to thigh muscle mass as estimated by dual-energy X-ray absorptiometry. These findings illustrate that there is still remaining precondition to further investigate this subject in order to properly understand the underlying factors related to force and power output between different body composition categories. However, it has to be noted that measurement equipment, techniques and angular velocities to assess force and power production were different in most of these studies except the one performed by Rauch et al. (Rauch et al., 2012) which used the same force plate as the current study. The greater absolute peak force and power production are connected to the idea that leg muscles of the obese subjects are responsible for carrying the extra weight. This is considered a training stimulus, triggering an increased muscular hypertrophy, increased muscle unit firing rate and an enhanced muscle unit synchronization (Bosco, Rusko, \& Hirvonen, 1986; Thorén, Seliger, Máček, Vávra, \& Rutenfranz, 1973). If the "general" assumption that a larger muscle could produce greater force is accurate, and considering the relationship between these two parameters, the obesity-associated extra amount of muscle mass could then contribute to a greater absolute force and power output. Yet, force and power output could also be dependent on the muscle fiber type ratio (Clark, Alloosh, Wenzel, Sturek, \& Kostrominova, 2011). However, reports have questioned this supposition showing that it might have only minimal effects on muscle tension (Ballak, Degens, Buse-Pot, de Haan, \& Jaspers, 2014). On the other hand, the extra loading of the body contributes to a decline in acceleration and therefore a decrease in jump height and running velocity. 
This assumption is explained by Newton's second law where the acceleration corresponds to the ratio between force and mass. Although acceleration was not measured in the present study, it might be speculated that the ground contact time for take-off during the $\mathrm{CMJ}$ and for loading, propulsion, and recovery during the running phases would be longer among the obese cohort. A recent study conducted by Yan and colleagues (2017) found that propulsion time while running at a slower pace was longer in obese children compared to non-obese peers (Yan, Wang, \& Zhang, 2017). In contrast, diminutions in body weight have proven opposite outcomes, reducing the ground contact time and increasing flight time during running, which resulted in performance amelioration (Kratky \& Muller, 2013). Furthermore, no main effect of gender on peak force production was found in the current study, but this effect was present for peak power. The increment rate of peak power production among body composition categories in boys was greater compared to girls. Similar results with better performance among boys were found for CMJ height and 20-m sprint time. Miller and colleagues (Miller, MacDougall, Tarnopolsky, \& Sale, 1993) argue that males have larger all fibre type cross-sectional areas compared to girls, whereas in females a greater non-contractile tissue presence was observed (Agyapong-Badu et al., 2014). The significantly higher amount of body fat percentage which was present in girls would contribute to the better performance achieved by boys compared to girls.

It has been suggested that running and jumping are fundamental skills for an active participation in games and sports (Wrotniak, Epstein, Dorn, Jones, \& Kondilis, 2006). Scientific evidence suggests that overweight and obese youth have lower levels of fundamental movement skills and poorer motor competence compared to normal weight peers (Han, Fu, Cobley, \& Sanders, 2018). Improving running and jumping skills among this category could be a good intervention strategy to improve their motor competence, and therefore increase participation in physical activity, organized sports and improve physical fitness (Cairney et al., 2005; Haga, 2009; Vedul-Kjelsas, Sigmundsson, Stensdotter, \& Haga, 2012; Wrotniak et al., 2006). Based on the physical activity guidelines, in order to achieve positive health benefits, it is recommended that adolescents should accumulate at least 60 minutes/day moderate- to vigorous aerobic physical activity, incorporating also strength exercises at least 3 times/week (Janssen \& Leblanc, 2010). For obese subjects, this could be a tangible challenge. A considerable number of constraints have to be taken into account when it comes to regular participation in physical activity (Flynn et al., 2006). In obese individuals, participation in physical activity is complicated by additional emotional barriers such as perceived weight status, consciousness of weight stigma, lack of motivation, and low perceived motor competence (Ball, Crawford, \& Owen, 2000; Lerner, Shultz et al., 2014; Storch et al., 2007; Sykes \& McPhail, 2008). These obvious challenges lead to decreased daily physical activity, creating a negative vicious cycle with detrimental consequences on their health status in many aspects. 
For instance, in the current study there was a higher rate of limb asymmetry among obese adolescents. By measuring LSI, strength and functional imbalances particularly for the lower limbs can be detected (Noyes, Barber, \& Mangine, 1991). While in sports LSI is considered an important injury prediction factor (McGrath et al., 2016), where athletes have to undertake various movement patterns at different velocities. In healthy non-athletic youth and older-aged subjects, this needs to be further investigated (Barber, Noyes, Mangine, McCloskey, \& Hartman, 1990; Ceroni, Martin, Delhumeau, \& Farpour-Lambert, 2012).

In a study conducted by Nicolozakes and associates a negative relationship between body fat percentage and functional movement screening (FMS $\left.{ }^{\mathrm{TM}}\right)$ test scores have been found (Nicolozakes, Schneider, Roewer, Borchers, \& Hewett, 2018). $\mathrm{FMS}^{\mathrm{TM}}$ is an instrument that may be used to identify movement asymmetries and deficiencies, but not for the lower extremities like LSI (Cook, Burton, Hoogenboom, \& Voight, 2014a, 2014b). A recent systematic review and meta-analysis concluded that individuals being classified at a "high risk" category by the $\mathrm{FMS}^{\mathrm{TM}}$ are $51 \%$ more likely to be affected by an injury compared to those who have a better score (Bunn, Rodrigues, \& Bezerra da Silva, 2019). Taking into account children and adolescent's systematic participation in physical education classes, the risk of injury might become a current and longitudinal burden for the health care system because of health-giving interventions. Indeed, it has been shown that excess body fat in adolescence and young adulthood increases the risk of costly injuries in the knee (Frilander et al., 2016) as well as spine (Goodbody, Sankar, \& Flynn, 2017). However, due to a lack of sufficient longitudinal research on this field, conclusions should be made with caution. Further studies should focus on collecting LSI data for non-athletic children and adolescents and its relationship to injury incidence.

\section{Study Limitations}

Although there were no significant age differences between body composition categories, and all participants were 9th-grade pupils, data related to biological maturation of the study participants were not collected. It has been shown previously that biological maturation plays an important role when it comes to physical fitness, be it health- or skill-related (De Ste Croix, Armstrong, Welsman, \& Sharpe, 2002; Seger \& Thorstensson, 2000). Considering the age of the participants, this could perhaps to some extent affect only the performance in boys as the peak height velocity is achieved at a later stage compared to girls (Handelsman, 2017; Tanner \& Davies, 1985). However, such cases with obvious delayed biological maturation were not observed during the data collection process. In addition, a considerable number of studies relate force and power results corresponding to FFM. The present study did not perform such analysis. The relative values were calculated only in relation to the total body mass of the participants. It is common knowledge that almost every individual perceives having a dominant limb which is assumed to create a greater force and power 
output. However, in the present study, data have been described for right and left limbs, rather than the self-described dominance. Indeed, it is particularly challenging to predict the dominant and non-dominant side (Stephens II, Lawson, DeVoe, \& Reiser II, 2007), and it has been shown that subjective expression of leg dominance cannot be used as a predictor for vertical jumping performance (Ceroni et al., 2012).

\section{Conclusion}

Findings of this study revealed that force and power production differ between body composition categories, with obese subjects having the lowest performance scores when results are expressed in relative terms. Most importantly, a slightly higher LSI was detected among obese adolescents adding to the deleterious biomechanical and functional effects of childhood obesity. Due to the small sample size in the overweight and obese categories there is a need to confirm the findings in larger populations in these categories. More precise tests for determining asymmetries and segmental body composition might help to further unravel the underlying cause for the increase in asymmetries with an increase in BMI. Nevertheless, with consideration of anthropometric characteristics, the assessment of ground reaction forces might provide an accurate approach for the assessment, screening and monitoring motor performance as well as bilateral differences in children and adolescents which could help a superior and safe designing and prescription of physical activities and physical education classes.

\section{Acknowledgements}

The authors would like to thank all the participants, parents, school principals and physical education teachers for their time and support. Furthermore, our special thanks go to the Faculty of Physical Education and Sports, University of Pristina, Kosovo for their kind support in using the equipment for data collection and testing.

\section{Authors' Contributions}

BW acted as the principal investigator of the current study, helped in designing the study, supervised the procedure for data collection and quality control, performed the statistical analysis, and assisted in writing the paper. FT was the team leader for the implementation, data collection, school identification, filled the ethics committee application form providing the necessary documents, and also contributed for analyzing the data and writing the paper. HT helped in designing the study, interpreting the data and writing the paper. IS, MG gave their valued impact for data collection and data quality control. All authors have read, edited, and approved the final version of the manuscript.

\section{Funding}

This study was supported by the Centre for Social Innovation, Vienna, Austria 
in the framework of the project Higher KOS-Promoting Institutional Development in Higher Education and Research in Kosovo (project number K-14-2012). Open access funding provided by University of Vienna.

\section{Conflicts of Interest}

The authors declare no conflicts of interest regarding the publication of this paper.

\section{References}

Abdelmoula, A., Martin, V., Bouchant, A., Walrand, S., Lavet, C., Taillardat, M., Maffiuletti, N. A., Boisseau, N., Duche, P., \& Ratel, S. (2012). Knee Extension Strength in Obese and Nonobese Male Adolescents. Applied Physiology, Nutrition, and Metabolism, 37, 269-275. https://doi.org/10.1139/h2012-010

Agyapong-Badu, S., Warner, M., Samuel, D., Narici, M., Cooper, C., \& Stokes, M. (2014). Anterior Thigh Composition Measured Using Ultrasound Imaging to Quantify Relative Thickness of Muscle and Non-Contractile Tissue: A Potential Biomarker for Musculoskeletal Health. Physiological Measurement, 35, 2165-2176.

https://doi.org/10.1088/0967-3334/35/10/2165

American College of Sports Medicine (2010). ACSM's Guidelines for Exercise Testing and Prescription, 8th Ed + ACSM's Certification Review (3rd ed.). Philadelphia, PA: Lippincott Williams \& Wilkins.

Ball, K., Crawford, D., \& Owen, N. (2000). Too Fat to Exercise? Obesity as a Barrier to Physical Activity. Australian and New Zealand Journal of Public Health, 24, 331-333. https://doi.org/10.1111/j.1467-842X.2000.tb01579.x

Ballak, S. B., Degens, H., Buse-Pot, T., de Haan, A., \& Jaspers, R. T. (2014). Plantaris Muscle Weakness in Old Mice: Relative Contributions of Changes in Specific Force, Muscle Mass, Myofiber Cross-Sectional Area, and Number. AGE (Dordr), 36, Article No. 9726. https://doi.org/10.1007/s11357-014-9726-0

Barber, S. D., Noyes, F. R., Mangine, R. E., McCloskey, J. W., \& Hartman, W. (1990). Quantitative Assessment of Functional Limitations in Normal and Anterior Cruciate Ligament-Deficient Knees. Clinical Orthopaedics and Related Research, 255, 204-214. https://doi.org/10.1097/00003086-199006000-00028

Bell, D. R., Sanfilippo, J. L., Binkley, N., \& Heiderscheit, B. C. (2014). Lean Mass Asymmetry Influences Force and Power Asymmetry during Jumping in Collegiate Athletes. The Journal of Strength \& Conditioning Research, 28, 884-891. https://doi.org/10.1519/JSC.0000000000000367

Blimkie, C. J., Sale, D. G., \& Bar-Or, O. (1990). Voluntary Strength, Evoked Twitch Contractile Properties and Motor Unit Activation of Knee Extensors in Obese and Non-Obese Adolescent Males. European Journal of Applied Physiology and Occupational Physiology, 61, 313-318. https://doi.org/10.1007/BF00357619

Boreham, C., \& Riddoch, C. (2001). The Physical Activity, Fitness and Health of Children. Journal of Sports Sciences, 19, 915-929. https://doi.org/10.1080/026404101317108426

Bosco, C., Rusko, H., \& Hirvonen, J. (1986). The Effect of Extra-Load Conditioning on Muscle Performance in Athletes. Medicine \& Science in Sports \& Exercise, 18, 415-419. https://doi.org/10.1249/00005768-198608000-00009

Bout-Tabaku, S., Klieger, S. B., Wrotniak, B. H., Sherry, D. D., Zemel, B. S., \& Stettler, N. (2014). Adolescent Obesity, Joint Pain, and Hypermobility. Pediatric Rheumatology, 
12, Article No. 11. https://doi.org/10.1186/1546-0096-12-11

Buckeridge, E., Hislop, S., Bull, A., \& McGregor, A. (2012). Kinematic Asymmetries of the Lower Limbs during Ergometer Rowing. Medicine \& Science in Sports \& Exercise, 44, 2147-2153. https://doi.org/10.1249/MSS.0b013e3182625231

Bunn, P. D. S., Rodrigues, A. I., \& Bezerra da Silva, E. (2019). The Association between the Functional Movement Screen Outcome and the Incidence of Musculoskeletal Injuries: A Systematic Review with Meta-Analysis. Physical Therapy in Sport, 35, 146-158. https://doi.org/10.1016/j.ptsp.2018.11.011

Cairney, J., Hay, J. A., Faught, B. E., Wade, T. J., Corna, L., \& Flouris, A. (2005). Developmental Coordination Disorder, Generalized Self-Efficacy toward Physical Activity, and Participation in Organized and Free Play Activities. Journal of Pediatrics, 147, 515-520. https://doi.org/10.1016/j.jpeds.2005.05.013

Castro-Pinero, J., Gonzalez-Montesinos, J. L., Keating, X. D., Mora, J., Sjostrom, M., \& Ruiz, J. R. (2010). Percentile Values for Running Sprint Field Tests in Children Ages 6 17 Years: Influence of Weight Status. Research Quarterly for Exercise and Sport, 81, 143-151. https://doi.org/10.1080/02701367.2010.10599661

Castro-Pinero, J., Gonzalez-Montesinos, J. L., Mora, J., Keating, X. D., Girela-Rejon, M. J., Sjostrom, M., \& Ruiz, J. R. (2009). Percentile Values for Muscular Strength Field Tests in Children Aged 6 to 17 Years: Influence of Weight Status. The Journal of Strength \& Conditioning Research, 23, 2295-2310. https://doi.org/10.1519/JSC.0b013e3181b8d5c1

Cavagna, G. A. (1975). Force Platforms as Ergometers. Journal of Applied Physiology, 39, 174-179. https://doi.org/10.1152/jappl.1975.39.1.174

Ceroni, D., Martin, X. E., Delhumeau, C., \& Farpour-Lambert, N. J. (2012). Bilateral and Gender Differences during Single-Legged Vertical Jump Performance in Healthy Teenagers. The Journal of Strength \& Conditioning Research, 26, 452-457.

https://doi.org/10.1519/JSC.0b013e31822600c9

Clark, B. A., Alloosh, M., Wenzel, J. W., Sturek, M., \& Kostrominova, T. Y. (2011). Effect of Diet-Induced Obesity and Metabolic Syndrome on Skeletal Muscles of Ossabaw Miniature Swine. American Journal of Physiology-Endocrinology and Metabolism, 300, E848-857. https://doi.org/10.1152/ajpendo.00534.2010

Cole, T. J., Bellizzi, M. C., Flegal, K. M., \& Dietz, W. H. (2000). Establishing a Standard Definition for Child Overweight and Obesity Worldwide: International Survey. BMJ, 320, 1240-1243. https://doi.org/10.1136/bmj.320.7244.1240

Cole, T. J., Flegal, K. M., Nicholls, D., \& Jackson, A. A. (2007). Body Mass Index Cut Offs to Define Thinness in Children and Adolescents: International Survey. BMJ, 335, 194. https://doi.org/10.1136/bmj.39238.399444.55

Collaboration, N. C. D. R. F. (2017). Worldwide Trends in Body-Mass Index, Underweight, Overweight, and Obesity from 1975 to 2016: A Pooled Analysis of 2416 Population-Based Measurement Studies in 128.9 Million Children, Adolescents, and Adults. The Lancet, 390, 2627-2642. https://doi.org/10.1016/S0140-6736(17)32129-3

Cook, G., Burton, L., Hoogenboom, B. J., \& Voight, M. (2014a). Functional Movement Screening: The Use of Fundamental Movements as an Assessment of Function-Part 2. International Journal of Sports Physical Therapy, 9, 549-563.

Cook, G., Burton, L., Hoogenboom, B. J., \& Voight, M. (2014b). Functional Movement Screening: The Use of Fundamental Movements as an Assessment of Function-Part 1. International Journal of Sports Physical Therapy, 9, 396-409.

De Ste Croix, M. B., Armstrong, N., Welsman, J. R., \& Sharpe, P. (2002). Longitudinal 
Changes in Isokinetic Leg Strength in 10 - 14-Year-Olds. Annals of Human Biology, 29, 50-62. https://doi.org/10.1080/03014460110057981

Duche, P., Ducher, G., Lazzer, S., Dore, E., Tailhardat, M., \& Bedu, M. (2002). Peak Power in Obese and Nonobese Adolescents: Effects of Gender and Braking Force. Medicine \& Science in Sports \& Exercise, 34, 2072-2078. https://doi.org/10.1097/00005768-200212000-00031

Dwyer, T., Magnussen, C. G., Schmidt, M. D., Ukoumunne, O. C., Ponsonby, A. L., Raitakari, O. T., Zimmet, P. Z., Blair, S. N., Thomson, R., Cleland, V. J., \& Venn, A. (2009). Decline in Physical Fitness from Childhood to Adulthood Associated with Increased Obesity and Insulin Resistance in Adults. Diabetes Care, 32, 683-687. https://doi.org/10.2337/dc08-1638

Flynn, M. A., McNeil, D. A., Maloff, B., Mutasingwa, D., Wu, M., Ford, C., \& Tough, S. C. (2006). Reducing Obesity and Related Chronic Disease Risk in Children and Youth: A Synthesis of Evidence with "Best Practice" Recommendations. Obesity Reviews, 7, 7-66. https://doi.org/10.1111/j.1467-789X.2006.00242.x

Fort-Vanmeerhaeghe, A., Bishop, C., Busca, B., Aguilera-Castells, J., Vicens-Bordas, J., \& Gonzalo-Skok, O. (2020). Inter-Limb Asymmetries Are Associated with Decrements in Physical Performance in Youth Elite Team Sports Athletes. PLOS ONE, 15, e0229440. https://doi.org/10.1371/journal.pone.0229440

Frilander, H., Viikari-Juntura, E., Heliovaara, M., Mutanen, P., Mattila, V. M., \& Solovieva, S. (2016). Obesity in Early Adulthood Predicts Knee Pain and Walking Difficulties among Men: A Life Course Study. European Journal of Pain, 20, 1278-1287. https://doi.org/10.1002/ejp.852

Garcia-Vicencio, S., Martin, V., Kluka, V., Cardenoux, C., Jegu, A. G., Fourot, A. V., Coudeyre, E., \& Ratel, S. (2015). Obesity-Related Differences in Neuromuscular Fatigue in Adolescent Girls. European Journal of Applied Physiology, 115, 2421-2432. https://doi.org/10.1007/s00421-015-3222-9

Gidding, S. S., Nehgme, R., Heise, C., Muscar, C., Linton, A., \& Hassink, S. (2004). Severe Obesity Associated with Cardiovascular Deconditioning, High Prevalence of Cardiovascular Risk Factors, Diabetes Mellitus/Hyperinsulinemia, and Respiratory Compromise. Journal of Pediatrics, 144, 766-769. https://doi.org/10.1016/S0022-3476(04)00243-4

Goodbody, C. M., Sankar, W. N., \& Flynn, J. M. (2017). Presentation of Adolescent Idiopathic Scoliosis: The Bigger the Kid, the Bigger the Curve. Journal of Pediatric Orthopaedics, 37, 41-46. https://doi.org/10.1097/BPO.0000000000000580

Goulding, A., Jones, I. E., Taylor, R. W., Piggot, J. M., \& Taylor, D. (2003). Dynamic and Static Tests of Balance and Postural Sway in Boys: Effects of Previous Wrist Bone Fractures and High Adiposity. Gait \& Posture, 17, 136-141.

https://doi.org/10.1016/S0966-6362(02)00161-3

Grimes, P., \& Legg, S. (2004). Musculoskeletal Disorders (MSD) in School Students as a Risk Factor for Adult MSD: A Review of the Multiple Factors Affecting Posture, Comfort and Health in Classroom Environments. Journal of the Human-Environment System, 7, 1-9. https://doi.org/10.1618/jhes.7.1

Guddal, M. H., Stensland, S. O., Smastuen, M. C., Johnsen, M. B., Heuch, I., Zwart, J. A., \& Storheim, K. (2020). Obesity in Young Adulthood: The Role of Physical Activity Level, Musculoskeletal Pain, and Psychological Distress in Adolescence (The HUNT-Study). International Journal of Environmental Research and Public Health, 17, 4603 https://doi.org/10.3390/ijerph17124603

Haga, M. (2009). Physical Fitness in Children with High Motor Competence Is Different 
from That in Children with Low Motor Competence. Physical Therapy, 89, 1089-1097. https://doi.org/10.2522/ptj.20090052

Han, A., Fu, A., Cobley, S., \& Sanders, R. H. (2018). Effectiveness of Exercise Intervention on Improving Fundamental Movement Skills and Motor Coordination in Overweight/Obese Children and Adolescents: A Systematic Review. Journal of Science and Medicine in Sport, 21, 89-102. https://doi.org/10.1016/j.jsams.2017.07.001

Handelsman, D. J. (2017). Sex Differences in Athletic Performance Emerge Coinciding with the Onset of Male Puberty. Clinical Endocrinology (Oxf), 87, 68-72. https://doi.org/10.1111/cen.13350

Hills, A. P., \& Parker, A. W. (1992). Locomotor Characteristics of Obese Children. Child: Care, Health and Development, 18, 29-34. https://doi.org/10.1111/j.1365-2214.1992.tb00338.x

Janssen, I., \& Leblanc, A. G. (2010). Systematic Review of the Health Benefits of Physical Activity and Fitness in School-Aged Children and Youth. International Journal of Behavioral Nutrition and Physical Activity, 7, Article No. 40. https://doi.org/10.1186/1479-5868-7-40

Kratky, S., \& Muller, E. (2013). Sprint Running with a Body-Weight Supporting Kite Reduces Ground Contact Time in Well-Trained Sprinters. The Journal of Strength \& Conditioning Research, 27, 1215-1222. https://doi.org/10.1519/JSC.0b013e3182654a30

Lafortuna, C. L., Fumagalli, E., Vangeli, V., \& Sartorio, A. (2002). Lower Limb Alactic Anaerobic Power Output Assessed with Different Techniques in Morbid Obesity. Journal of Endocrinological Investigation, 25, 134-141. https://doi.org/10.1007/BF03343977

Lafortuna, C. L., Maffiuletti, N. A., Agosti, F., \& Sartorio, A. (2005). Gender Variations of Body Composition, Muscle Strength and Power Output in Morbid Obesity. International Journal of Obesity (Lond), 29, 833-841. https://doi.org/10.1038/sj.ijo.0802955

Lake, J., Mundy, P., Comfort, P., McMahon, J. J., Suchomel, T. J., \& Carden, P. (2018). Concurrent Validity of a Portable Force Plate Using Vertical Jump Force-Time Characteristics. Journal of Applied Biomechanics, 34, 410-413. https://doi.org/10.1123/jab.2017-0371

Laurson, K. R., Saint-Maurice, P. F., Welk, G. J., \& Eisenmann, J. C. (2017). Reference Curves for Field Tests of Musculoskeletal Fitness in U.S. Children and Adolescents: The 2012 NHANES National Youth Fitness Survey. The Journal of Strength \& Conditioning Research, 31, 2075-2082. https://doi.org/10.1519/JSC.0000000000001678

Lazzer, S., Pozzo, R., Rejc, E., Antonutto, G., \& Francescato, M. P. (2009). Maximal Explosive Muscle Power in Obese and Non-Obese Prepubertal Children. Clinical Physiology and Functional Imaging, 29, 224-228.

https://doi.org/10.1111/j.1475-097X.2009.00863.x

Lee, S., Guerra, N., \& Arslanian, S. (2010). Skeletal Muscle Lipid Content and Insulin Sensitivity in Black versus White Obese Adolescents: Is There a Race Differential? The Journal of Clinical Endocrinology \& Metabolism, 95, 2426-2432. https://doi.org/10.1210/jc.2009-2175

Lerner, Z. F., Board, W. J., \& Browning, R. C. (2014). Effects of Obesity on Lower Extremity Muscle Function during Walking at Two Speeds. Gait \& Posture, 39, 978-984. https://doi.org/10.1016/j.gaitpost.2013.12.020

Lerner, Z. F., Shultz, S. P., Board, W. J., Kung, S., \& Browning, R. C. (2014). Does Adiposity Affect Muscle Function during Walking in Children? Journal of Biomechanics, 47, 2975-2982. https://doi.org/10.1016/j.jbiomech.2014.07.006

Loftin, M., Sothern, M., Trosclair, L., O’Hanlon, A., Miller, J., \& Udall, J. (2001). Scaling 
$\mathrm{VO}_{2}$ Peak in Obese and Non-Obese Girls. Obesity Research, 9, 290-296. https://doi.org/10.1038/oby.2001.36

Luk, H. Y., Winter, C., O’Neill, E., \& Thompson, B. A. (2014). Comparison of Muscle Strength Imbalance in Powerlifters and Jumpers. The Journal of Strength \& Conditioning Research, 28, 23-27. https://doi.org/10.1519/JSC.0b013e318295d311

Machado, D., Oikawa, S., \& Barbanti, V. (2013). The Multicomponent Anthropometric Model for Assessing Body Composition in a Male Pediatric Population: A Simultaneous Prediction of Fat Mass, Bone Mineral Content, and Lean Soft Tissue. Journal of Obesity, 2013, Article ID: 428135. https://doi.org/10.1155/2013/428135

Madruga-Parera, M., Romero-Rodriguez, D., Bishop, C., Beltran-Valls, M. R., Latinjak, A. T., Beato, M., \& Fort-Vanmeerhaeghe, A. (2019). Effects of Maturation on Lower Limb Neuromuscular Asymmetries in Elite Youth Tennis Players. Sports (Basel), 7, 106. https://doi.org/10.3390/sports7050106

Maffeis, C., Zaffanello, M., \& Schutz, Y. (1997). Relationship between Physical Inactivity and Adiposity in Prepubertal Boys. Journal of Pediatrics, 131, 288-292. https://doi.org/10.1016/S0022-3476(97)70168-9

Maffiuletti, N. A., Jubeau, M., Agosti, F., De Col, A., \& Sartorio, A. (2008). Quadriceps Muscle Function Characteristics in Severely Obese and Nonobese Adolescents. European Journal of Applied Physiology, 103, 481-484. https://doi.org/10.1007/s00421-008-0737-3

Mala, L., Maly, T., Cabell, L., Hank, M., Bujnovsky, D., \& Zahalka, F. (2020). Anthropometric, Body Composition, and Morphological Lower Limb Asymmetries in Elite Soccer Players: A Prospective Cohort Study. International Journal of Environmental Research and Public Health, 17, 1140. https://doi.org/10.3390/ijerph17041140

Maly, T., Zahalka, F., Mala, L., \& Cech, P. (2015). The Bilateral Strength and Power Asymmetries in Untrained Boys. Open Medicine, 10, 224-232.

https://doi.org/10.1515/med-2015-0034

McGrath, T. M., Waddington, G., Scarvell, J. M., Ball, N. B., Creer, R., Woods, K., \& Smith, D. (2016). The Effect of Limb Dominance on Lower Limb Functional Performance-A Systematic Review. Journal of Sports Sciences, 34, 289-302. https://doi.org/10.1080/02640414.2015.1050601

Miller, A. E., MacDougall, J. D., Tarnopolsky, M. A., \& Sale, D. G. (1993). Gender Differences in Strength and Muscle Fiber Characteristics. European Journal of Applied Physiology and Occupational Physiology, 66, 254-262. https://doi.org/10.1007/BF00235103

Mukaka, M. M. (2012). Statistics Corner: A Guide to Appropriate Use of Correlation Coefficient in Medical Research. Malawi Medical Journal, 24, 69-71.

Nicolozakes, C. P., Schneider, D. K., Roewer, B. D., Borchers, J. R., \& Hewett, T. E. (2018). Influence of Body Composition on Functional Movement Screen Scores in College Football Players. Journal of Sport Rehabilitation, 27, 431-437. https://doi.org/10.1123/jsr.2015-0080

Noyes, F. R., Barber, S. D., \& Mangine, R. E. (1991). Abnormal Lower Limb Symmetry Determined by Function Hop Tests after Anterior Cruciate Ligament Rupture. The American Journal of Sports Medicine, 19, 513-518. https://doi.org/10.1177/036354659101900518

O’Malley, G., Hussey, J., \& Roche, E. (2012). A Pilot Study to Profile the Lower Limb Musculoskeletal Health in Children with Obesity. Pediatric Physical Therapy, 24, 292-298. https://doi.org/10.1097/PEP.0b013e31825c14f8

Paterno, M. V., Schmitt, L. C., Ford, K. R., Rauh, M. J., Myer, G. D., Huang, B., \& Hewett, T. E. (2010). Biomechanical Measures during Landing and Postural Stability Predict 
Second Anterior Cruciate Ligament Injury after Anterior Cruciate Ligament Reconstruction and Return to Sport. The American Journal of Sports Medicine, 38, 1968-1978. https://doi.org/10.1177/0363546510376053

Rauch, R., Veilleux, L. N., Rauch, F., Bock, D., Welisch, E., Filler, G., Robinson, T., Burrill, E., \& Norozi, K. (2012). Muscle Force and Power in Obese and Overweight Children. Journal of Musculoskeletal and Neuronal Interactions, 12, 80-83.

Rodriguez Valero, F. J., Gualteros, J. A., Torres, J. A., Umbarila Espinosa, L. M., \& Ramirez-Velez, R. (2015). [Association between Muscular Fitness and Physical Health Status among Children and Adolescents from Bogota, Colombia]. Nutrición Hospitalaria, 32, 1559-1566.

Schmitt, L. C., Paterno, M. V., Ford, K. R., Myer, G. D., \& Hewett, T. E. (2015). Strength Asymmetry and Landing Mechanics at Return to Sport after Anterior Cruciate Ligament Reconstruction. Medicine \& Science in Sports \& Exercise, 47, 1426-1434. https://doi.org/10.1249/MSS.0000000000000560

Seger, J. Y., \& Thorstensson, A. (2000). Muscle Strength and Electromyogram in Boys and Girls Followed through Puberty. European Journal of Applied Physiology, 81, 54-61. https://doi.org/10.1007/PL00013797

Shimizu, T., Samaan, M. A., Tanaka, M. S., Pedoia, V., Souza, R. B., Li, X., \& Ma, C. B. (2019). Abnormal Biomechanics at 6 Months Are Associated With Cartilage Degeneration at 3 Years after Anterior Cruciate Ligament Reconstruction. Arthroscopy, 35, 511-520.

Shultz, S. P., Hills, A. P., Sitler, M. R., \& Hillstrom, H. J. (2010). Body Size and Walking Cadence Affect Lower Extremity Joint Power in Children's Gait. Gait \& Posture, 32, 248-252. https://doi.org/10.1016/j.gaitpost.2010.05.001

Smith, J. J., Eather, N., Morgan, P. J., Plotnikoff, R. C., Faigenbaum, A. D., \& Lubans, D. R. (2014). The Health Benefits of Muscular Fitness for Children and Adolescents: A Systematic Review and Meta-Analysis. Sports Medicine, 44, 1209-1223. https://doi.org/10.1007/s40279-014-0196-4

Steidl-Muller, L., Hildebrandt, C., Muller, E., Fink, C., \& Raschner, C. (2018). Limb Symmetry Index in Competitive Alpine Ski Racers: Reference Values and Injury Risk Identification According to Age-Related Performance Levels. Journal of Sport and Health Science, 7, 405-415. https://doi.org/10.1016/j.jshs.2018.09.002

Stephens II, T. M., Lawson, B. R., DeVoe, D. E., \& Reiser II, R. F. (2007). Gender and Bilateral Differences in Single-Leg Countermovement Jump Performance with Comparison to a Double-Leg Jump. Journal of Applied Biomechanics, 23, 190-202. https://doi.org/10.1123/jab.23.3.190

Storch, E. A., Milsom, V. A., Debraganza, N., Lewin, A. B., Geffken, G. R., \& Silverstein, J. H. (2007). Peer Victimization, Psychosocial Adjustment, and Physical Activity in Overweight and At-Risk-for-Overweight Youth. Journal of Pediatric Psychology, 32, 80-89. https://doi.org/10.1093/jpepsy/jsj113

Sykes, H., \& McPhail, D. (2008). Unbearable Lessons: Contesting Fat Phobia in Physical Education. Sociology of Sport Journal, 25, 66-96. https://doi.org/10.1123/ssj.25.1.66

Tanner, J. M., \& Davies, P. S. (1985). Clinical Longitudinal Standards for Height and Height Velocity for North American Children. Journal of Pediatrics, 107, 317-329. https://doi.org/10.1016/S0022-3476(85)80501-1

Thivel, D., Isacco, L., Lazaar, N., Aucouturier, J., Ratel, S., Dore, E., Meyer, M., \& Duche, P. (2011). Effect of a 6-Month School-Based Physical Activity Program on Body Composition and Physical Fitness in Lean and Obese Schoolchildren. European Journal of Pediatrics, 170, 1435-1443. https://doi.org/10.1007/s00431-011-1466-x 
Thorén, C., Seliger, V., Máček, M., Vávra, J., \& Rutenfranz, J. (1973). The Influence of Training on Physical Fitness in Healthy Children and Children with Chronic Diseases. In F. Linneweh (Ed.), Current Aspects of Perinatology and Physiology of Children (pp. 83-112). Berlin, Heidelberg: Springer. https://doi.org/10.1007/978-3-642-61956-4_6

Trivers, R., Fink, B., Russell, M., McCarty, K., James, B., \& Palestis, B. G. (2014). Lower Body Symmetry and Running Performance in Elite Jamaican Track and Field Athletes. PLoS ONE, 9, e113106. https://doi.org/10.1371/journal.pone.0113106

Tsiros, M. D., Coates, A. M., Howe, P. R., Grimshaw, P. N., Walkley, J., Shield, A., Mallows, R., Hills, A. P., Kagawa, M., Shultz, S., \& Buckley, J. D. (2013). Knee Extensor Strength Differences in Obese and Healthy-Weight 10- to 13-Year-Olds. European Journal of Applied Physiology, 113, 1415-1422. https://doi.org/10.1007/s00421-012-2561-z

Vedul-Kjelsas, V., Sigmundsson, H., Stensdotter, A. K., \& Haga, M. (2012). The Relationship between Motor Competence, Physical Fitness and Self-Perception in Children. Child: Care, Health and Development, 38, 394-402. https://doi.org/10.1111/j.1365-2214.2011.01275.x

Weststrate, J. A., \& Deurenberg, P. (1989). Body Composition in Children: Proposal for a Method for Calculating Body Fat Percentage from Total Body Density or Skinfold-Thickness Measurements. American Journal of Clinical Nutrition, 50, 1104-1115. https://doi.org/10.1093/ajcn/50.5.1104

Wrotniak, B. H., Epstein, L. H., Dorn, J. M., Jones, K. E., \& Kondilis, V. A. (2006). The Relationship between Motor Proficiency and Physical Activity in Children. Pediatrics, 118, e1758-e1765. https://doi.org/10.1542/peds.2006-0742

Yan, S.-H., Wang, L., \& Zhang, K. (2017). Effects of Different Movement Modes on Plantar Pressure Distribution Patterns in Obese and Non-Obese Chinese Children. Gait \& Posture, 57, 28-34. https://doi.org/10.1016/j.gaitpost.2017.05.001

Yoo, J. J., Cho, N. H., Lim, S. H., \& Kim, H. A. (2014). Relationships between Body Mass Index, Fat Mass, Muscle Mass, and Musculoskeletal Pain in Community Residents. Arthritis \& Rheumatology, 66, 3511-3520. https://doi.org/10.1002/art.38861 